\title{
Investigate Stress Levels of Nursing Students in First Oncology Clinical Experience
}

\author{
Elif Unsal Avdal ${ }^{1}$, Burcu Arkan ${ }^{2}$ and Berna Nilgun Ozgursoy Uran ${ }^{1^{*}}$ \\ ${ }^{1}$ Department of Nursing, Faculty of Health Science, Izmir Katip Celebi Universitesi, Turkey \\ ${ }^{2}$ Department of Nursing, Faculty of Health Science, Uludag University, Turkey
}

"Corresponding author: Berna Nilgun Ozgursoy Uran, Lecturer, Department of Nursing, Faculty of Health Science, Izmir Katip Celebi Universitesi, Turkey, Tel: 905445748771, E-mail: bernanilgun@gmail.com

Received date: February 15, 2017; Accepted date: April 5, 2017; Published date: April 12, 2017

Copyright: $\odot 2017$ Avdal EU, et al. This is an open-access article distributed under the terms of the Creative Commons Attribution License, which permits unrestricted use, distribution, and reproduction in any medium, provided the original author and source are credited.

\begin{abstract}
Purpose: To evaluate the stress level of second-year's nursing students during their first oncology clinical experience.

Methods: The descriptive study in order to determine the stress levels of second-year's nursing students. This study was conducted with the students of Uludag University. The study population was consisting of 156 nursing students attending second year class in nursing school. Pagana Clinical Stress Questionnaire (PCSQ) was used. Data in analysis of survey's results was evaluated mean, Pearson's correlation method, t-test was used in statistical analysis percentage.
\end{abstract}

Results: When a comparison is made between the mean score of clinical stress and socio-economic data of the students involved in the study; any meaningful difference has not been observed between the mean scores of stress and the sex, approaches to nursing profession, previous hospital experiences, health status whether having a chronic disease or not. Only meaningful difference $(p>0.05)$ has been observed with family member status whether working as a health worker or not $(p<0.05)$. The mean score of stress of students in the first clinical practice was found as $70 \pm 4.15$. This result exhibited that the students experienced stress is the average.

Conclusions: It was found that the nursing students had a high level of stress during the first clinical practice and experienced the most stress "fighting" dimension from the subscales. So, it was thought that the clinical orientation program must be done before student experience. Because clinical orientation program was effective to reduce the risk.

Keywords: Stress levels; Nursing students; Oncology; Clinical experience

\section{Introduction}

Clinical teaching is the most important basic part taking place in nursing education since it should be designed to enable the nursing students in both our country and the world. This method is require to "have knowledge" about the topics required in nursing functions and "have the ability" to perform these functions properly $[1,2]$.

Clinical setting provides the student with opportunities to cope with the general patient and concerning problems, to use theoretical knowledge in practice and make analysis, to become proficient in psychomotor and intellectual skills, to have critical thinking, to solve the problem, to make observation, to take decision, to participate in teamwork and to get ready for the next roles. However, the learning that occurs in the learning environment for nursing students presents challenges that may cause students to experience stress and anxiety [3-5].

Education works as a social process that aims to develop the personal and social skills of the student. On the other hand it includes a certain supervision structure in scope of planned and scheduled school activities. In nursing education, it is aimed at professionalization of students. This education programs is carried out in the school and hospital environments. Nursing students are faced with various problems as well as bringing by the age groups and student positions and the school and hospital environments. For these reasons, this education has potential stressors increasing the level of anxiety.

High levels of anxiety can affect students' clinical performance, presenting a clear threat to success in a clinical rotation. It is crucial for clinical nursing faculty to foster a supportive learning environment conducive to undergraduate nursing student learning [2].

The first clinical experience in nursing education is a factor of stress for students. The first clinical experiences do not only help the students to establish a link between theoretical knowledge and its applications but also allows the development of psychomotor skills that form the basis in nursing practice and the role of socializing [6].

Stress is defined as an important psycho-social factor affecting the student's academic performance and well-being during training. Therefore, a stressful student loses confidence of the patient since she will not able to observe the needs of the patient properly [3]. Clinical practice or education contributes the environment in which students come across stress, which can be assessed as challenging or difficult to manage, causing anxiety. This study was conducted to evaluate the 
stress level of second-year's nursing students during their first oncology clinical experience.

\section{Research Design and Methods}

\section{Objectives}

The aim of this study is to examine the clinical stress levels of nursing second year students as a result of their experiences in the first oncology clinic.

\section{Population and setting}

This study was conducted with the nursing students of a university hospital. The study population was consisting of 156 nursing students attending second year class in nursing school.During the fall semester of the second year of students in the nursing program of this university. After the first year internships, the internship for the second year was an important source of stress for the students due to the increasing number of clinics and the internship for chronic diseases. For this reason, researchers have found that nurse students from oncology clinics are very frightened, especially as a result of written feedback from students.

Because of that reason, we planned to investigate clinical stress levels as a result of first clinical oncology experiences of second year students who took internships all that year. In doing this study, we made nursing second year students practicing all internal internship to fulfill the condition of being in the oncology clinic at the end of the clinical rotations. We started the questionnaire study as written and verbal acknowledgment from the nursing students who agreed to participate in the study based on the voluntary principle.

\section{Data collection tools}

Cognitive appraisal of stress was measured using Pagana's Clinical Stress Questionnaire, the PCSQ , which is based on Folkman's an d Lazaru's Clinical Stress Questionnaire [7]. Pagana Clinical Stress Questionnaire (PCSQ), which was developed by Pagana in a questionnaire form consisting of 15 questions reflecting the sociodemographic characteristics of students then validated in terms of reliability and validity after oriented to Turkish by Merdiye Şendir ve Rengin Acaroğlu, was used in evaluation of the data. International consistency of the Turkish total questionnaire was coefficient 0.70 . In our study international consistency of the total questionnaire was coefficient 0.80 .

The maximum score of the scale is 80 , minimum score is 0 . The lower score indicates low level of stress and the high score is high level of stress. Clinical stress questionnaire (PCSQ) was used consisting of total of 20 questions including the emotions such as threats, fighting, loss of benefits to determine the initial value of the stress requiring the students- midwives and nurses to cope with during the first clinical experience. Each item is considered to be the fifth-grade; 0 - "no", 1 - "a little", 2 - "medium", 3 - "more", 4 - "too much". Based on the scores for each item, at least " 0 " up to " 80 " points can be obtained in survey. The lower score indicates low level of stress and the high score is high level of stress. The PCSQ takes approximately two minutes to complete.

\section{Statistical analysis}

Data collection tool was applied at the end of the last day in oncology clinical practice. Data in analysis of survey's results was evaluated in software SPSS 20.0; mean, Pearson's correlation method, t-test were used in statistical analysis percentage.

\section{Ethical Consideration}

The written consent was taken from Uludag University, Nursing School of Health Sciences for the data collection (No: 23561). In addition, by explaining the aim of the study, the verbal confirmation of the nursing students was also received and the confidentiality was respected.

\section{Results}

When the definitive characteristics of the students participated in our study were analysed, it is determined that the mean age of 156 students attending second-year class age is $20.08 \pm 2.14$. The other indicators involved in study are $62.3 \%$ of the students as female $37.7 \%$ as male.

As it is seen in Table 1, 85.2\% of the students participated in survey represents the students who choose the job willingly however the percentage of the students who have expressed that they enjoy their jobs is $88.4 \%$. The percentage by $55.1 \%$ has stated that there is no other health worker in their families.

On the other hand, $57.1 \%$ from the students has reported that they do not have any previous hospital experience, $49.4 \%$ are those who do not have any negative hospital experience before and the percentage by $92.5 \%$ has stated that they do not have any chronic disease (Table 1).

\begin{tabular}{|c|c|c|}
\hline Demographic Data & Number (N) & $\begin{array}{l}\text { Percentage } \\
(\%)\end{array}$ \\
\hline \multicolumn{3}{|l|}{ Sex } \\
\hline Female & 97 & 62.3 \\
\hline Male & 59 & 37.7 \\
\hline Who chosen the job willingly? & 95 & 60.9 \\
\hline Who did not choose the job willingly? & 61 & 39.1 \\
\hline Who enjoys the job? & 110 & 70.5 \\
\hline Who did not enjoy the job? & 46 & 29.5 \\
\hline $\begin{array}{l}\text { Who have another family member as health } \\
\text { worker? } \\
\text { Who do not have another family member as } \\
\text { health worker? }\end{array}$ & $\begin{array}{l}70 \\
86\end{array}$ & $\begin{array}{l}44.9 \\
55.1\end{array}$ \\
\hline Who have hospital experience before? & 67 & 42.9 \\
\hline Who do not have hospital experience before? & 89 & 57.1 \\
\hline Who have a negative hospital experience? & 79 & 50.6 \\
\hline $\begin{array}{l}\text { Who do not have a negative hospital } \\
\text { experience? }\end{array}$ & 77 & 49.4 \\
\hline Who have a chronic disease? & 11 & 7.5 \\
\hline Who do not have a chronic disease? & 145 & 92.5 \\
\hline
\end{tabular}

Table 1: Socio-Demographic Characteristics of Nursing Students (N: 156).

When a comparison is made between the mean score of clinical stress and socio-economic data of the students involved in the study; any meaningful difference has not been observed between the mean 
scores of stress and the sex, approaches to nursing profession, enjoying the job, previous hospital experiences, health status whether having a chronic disease or not. ( $\mathrm{p}>0.05)$ Only meaningful difference has been observed with family member status whether working as a health worker or not $(\mathrm{p}<0.05)($ Table 2$)$.

\begin{tabular}{|c|c|c|c|c|}
\hline Demographic Data & Number (N) & Percentage (\%) & $\begin{array}{l}\text { ( Stress Score ) } \\
X \pm S D\end{array}$ & Significance \\
\hline \multicolumn{5}{|l|}{ Sex } \\
\hline Female & 97 & 62.3 & $27.09 \pm 7.12$ & $t=0.465$ \\
\hline Male & 59 & 37.7 & $28.20 \pm 8.12$ & $p>0.05$ \\
\hline Who chosen the job willingly? & 95 & 60.9 & $28.18 \pm 6.22$ & $t=0.696$ \\
\hline Who did not choose the job willingly? & 61 & 39.1 & $29.10 \pm 7.14$ & $p>0.05$ \\
\hline Who enjoys the job? & 110 & 70.5 & $27.50 \pm 7.78$ & $\mathrm{t}=2.09$ \\
\hline Who did not enjoy the job? & 46 & 29.5 & $25.85 \pm 11.27$ & $p>0.05$ \\
\hline Who have another family member as health worker? & 70 & 44.9 & $28.00 \pm 5.55$ & $\mathrm{t}=0.185$ \\
\hline $\begin{array}{l}\text { Who do not have another family? member as health } \\
\text { worker }\end{array}$ & 86 & 55.1 & $20.52 \pm 7.80$ & $\mathrm{p}<0.05^{*}$ \\
\hline Who have hospital experience before? & 67 & 42.9 & $28.2 \pm 9.45$ & $\mathrm{t}=0.742$ \\
\hline Who do not have hospital experience before? & 89 & 57.1 & $28.0 \pm 7.44$ & $p>0.05$ \\
\hline Who have a negative hospital experience? & 79 & 50.6 & $28.54 \pm 5.56$ & $\mathrm{t}=0.117$ \\
\hline Who do not have a negative hospital experience? & 77 & 49.4 & $26.76 \pm 8.44$ & $p>0.05$ \\
\hline Who have a chronic disease? & 11 & 7.5 & $29.83 \pm 10.40$ & $t=1.672$ \\
\hline Who do not have a chronic disease? & 145 & 92.5 & $28.24 \pm 8.03$ & $p>0.05$ \\
\hline
\end{tabular}

Table 2: Comparison between socio-demographic data and stress score means of the nursing students (N: 156).

The values determined in scale are the average scale score of threat as $20.4 \pm 2.14$, The average scale score of fighting as $23.64 \pm 5.93$, the average scale score of damage as $20.32 \pm 2.99$ and the average scale score of benefit $16.70 \pm 3.44$ (Table 3 ).

\begin{tabular}{|c|c|c|c|}
\hline & Number (N) & Average & $\begin{array}{l}\text { Standard } \\
\text { Deviation }\end{array}$ \\
\hline \multicolumn{4}{|l|}{ Descriptive Statistics } \\
\hline $\begin{array}{l}\text { Clinical Stress } \\
\text { Score }\end{array}$ & 156 & 70 & 4.15 \\
\hline \multicolumn{4}{|l|}{ Scales } \\
\hline Threat Scale & 156 & 20.41 & 2.14 \\
\hline Fighting Scale & 156 & 23.64 & 5.93 \\
\hline Loss Scale & 156 & 20.32 & 2.99 \\
\hline Benefit Scale & 156 & 16.70 & 3.44 \\
\hline
\end{tabular}

Table 3: Students clinical stress score averages (N: 156).

\section{Discussion}

Because clinical practice is important for future professionals to acquire competence, a group of studies has focused exclusively on the analysis of these activities as sources of stress [8]. The clinical practices as the environments where have a great contribution in development of professional identity unquestionably and offer the students chances to be socialized towards this direction and enable the students to learn the culture of profession [9].

Studies have also reported that students experience anxiety during their practice on the first day of clinical practice [10-12]. In the study of Taşdelen and Zaybak, it was found that gender and intention to come to nursing school did not affect clinical stress level [13]. Similarly, in the study of Mankan, gender of students did not affect the stress levels of the first day of clinical practice, but voluntary selection has affected the clinical stress level [14]. In contrast, Aytekin et al., found that male students had more difficulties. Similar to the literature, it was also found that gender did not affect clinical stress level in our study [15]. Several studies indicate that clinical training is in an environment that may cause students to experience high levels of stress and anxiety, even if several studies indicate conversely [16,17].

In the study of Potur and Bilgin, there was no significant difference in clinic first and last day stress levels according to gender ( $p>0.05)$ [18]. When compared clinic first and last day stress levels in male and female students, The female student's harm and benefit mean scores and total PCSQ mean scores on the last day were significantly higher than those on the first day $(\mathrm{p}<0.05)$. Similarly, male students' harm and benefit mean scores and total PCSQ mean scores on the last day were significantly higher than those on the first day $(\mathrm{p}<0.05)$.

In the study conducted by Karabacak et al., it was found that the mean score of stress of students in the first clinical practice was $31.88 \pm$ 8.60 [19]. In another study, Çakırcalı et al. found the mean score of stress of students in the first clinical practice was found as $26.44 \pm 6.1$ [20]. Arabac1 found the mean pre-clinical, post-test and post-stress scores of the nursing students were $48.05 \pm 5.00,37.11 \pm 9.97$ and 
Page 4 of 5

$36.04 \pm 12.65$, respectively [21]. Taşdelen and Zaybak's study, it was determined that the average score of the students' clinical stress questionnaire was $33.96 \pm 10.2$. In the studies of Karagözoğlu et al., the nursing students mostly had found low clinical stress levels respectively $27.10 \pm 10.41,27.56 \pm 10.76$ and $26.13 \pm 10.10$ as scores of total questionnaire [22,23].

On the other hand, Atay and Yilmaz who used the same scale found the mean score of stress of the students in first practice as $54.2 \pm 8.9$; this value demonstrated that they experienced the stress above the average [24]. Erbil found the mean anxiety score as $57.62 \pm 8.46$ in nursing students who performed the first clinical practice. This value was observed in "medium" level thus it was reported that the first clinical experience was a factor increasing the anxiety in students. These studies evaluated the mean score of stress of students as a low level of stress as differently from our study, and students' clinical stress score in the first oncology clinical practice was found to be higher in our results. In our study the mean score of students' clinical stress in the first oncology clinical practice was found as $70 \pm 4.15$. This result exhibited that the students experienced quite high stress. The reasons for the different outcomes of this study are that the schools, circumstances, and hospitals are different.

In the study of Tasdelen and Zaybak, the subscale scores of the PCSQ were $9.48 \pm 4.58$ in the "threat" dimension, $14.24 \pm 5.08$ in the "fighting" dimension, $6.45 \pm 3.65$ in the "harm" dimension and $3.77 \pm$ 2.07 in the "benefit" dimension. Atay and Yilmaz determined the mean score of the scale sub-groups as follows; $23.2 \pm 5.6$ as score of fight; $15.2 \pm 4.8$ as score of threat, $9.7 \pm 3.5$ as score of damage and $6.08 \pm 1.8$ as score of benefit. In the study of Karagözoğlu, Özden and Yıldız, the subscale scores of the scale were $7.29 \pm 4.66$ in the "threat" dimension, $13.92 \pm 6.61$ in the "fighting" dimension, $2.45 \pm 3.16$ in the "harm" dimension and $3.44 \pm 1.95$ in the "benefit" dimension. In our study, these subscale averages are found higher. The average scale score of fighting as $23.64 \pm 5.93$, the average scale score of threat as $20.4 \pm 2.14$, the average scale score of damage as $20.32 \pm 2.99$ and the average scale score of benefit $16.70 \pm 3.44$. According to these results, unlike the literature, clinical stress was found to be higher in the students who were included in our study. But similar to the literature, it was found that students had the highest level of clinical stress due to fighting subscale and the lowest level of clinical stress due to benefit sub-scale.

It is seen that the stress developed in the first period of the clinical practice is higher than the other periods. It is thought that the first time students are in the clinical setting may cause them to feel insufficient in their nursing activities. And also this may be effective in the students' perception of the threat and the feeling of being beneficial.

\section{Conclusion}

As a result of the study to determine the stress levels of the students during the first clinical experience, it was found that the nursing students had a high level of stress during the first clinical practice and experienced the most stress "fighting" dimension from the subscales. For the purpose of clinical education, it had been decided to the conclusion that the level of stress associated with clinical practice decreased. It is also suggested that students should be educated on issues that they feel are inadequate for clinical practice in order to increase their self-confidence.

\section{Conflict of Interest}

The authors declare that there are no conflicts of interest.

\section{Acknowledgements}

We would like to express our students who supported the researchers in collecting study data.

\section{References}

1. Görgülü S (2002) Status of nursing practice fulfillment during the clinical practice of the students-I. Hacettepe University School of Nursing Journal 9: 1-20.

2. Moscaritolo LM (2009) Interventional strategies to decrease nursing student anxiety in the clinical learning environment. J Nurs Educ 48: 17-23.

3. Jimenez C, Navia-Osorio PM, Vacas Diaz CV (2010) Stress and health in novice and experienced nursing students. J Nurs Educ 66: 442-455.

4. Bektas HA (2004) Difficulties experienced in theoretical and practical training of nursing students and the expectations from the instructor. Nursing Forum: 45-54.

5. Görgülü S (2001) Expectations of the students from the instructors in clinical practice. Hacettepe University Journal of School Nursing 8: 1-13.

6. Sendir M, Acaroğlu R (2008) Reliability and validity of Turkish version of clinical stress questionnaire. Nurse Education Today 28: 737-743.

7. Pagana KD (1988) Stresses and threats reported by baccalaureate students in relation to an initial clinical experience. J Nurs Educ 27: 418-424.

8. Martos MP, Landa A, Zafra EL (2012) Sources of stress in nursing students: A systematic review of quantita $\neg$ tive studies. International Nursing Review 59: 15-25.

9. Dalton L (2005) Use of clinical space as an indicator of student nurse's professional development and changing need for support. Nurse Educ Today 25: 126-131.

10. Erbil N, Kahraman AN, Bostan O (2006) Determination of anxiety levels of nursing students before their first clinical experience. Anadolu Nursing and Health Sciences Review 9: 10-16.

11. Chan KLC, Winnie KW, Daniel YT (2009) Hong Kong baccalaureate nursing students stress and their coping strategies in clinical practice. J Prof Nurs 25: 307-313.

12. Tel H, Sabancıoğulları S (2004) Anxiety situations in first-year nursing students applying IM to each other during laboratory practice and on the first day of clinical practice. Journal of Ataturk University School of Nursing 7: 27-32.

13. Taşdelen S, Zaybak A (2013) Examination of the Stress Levels of Nursing Students According to the First Clinical Experience. F N Hem Derg 21: 101-106.

14. Mankan T, Polat H, Cengiz Z, Sevindik F (2016) The first clinical stress levels of nursing students and the affecting factors. İnönü University Health Science Magazine 5: 10-15.

15. Aytekin S, Özer FG, Beydağ, KD (2009) Denizli School of Health students' difficulties in clinical practice. Fırat Sağlık Hizmetleri Magazine 4: 137-149.

16. Sharif F, Masoumi S (2005) A qualitative study of nursing student experiences of clinical practice. BMC Nursing 4: 1-7.

17. Timmins F, Kaliszer M (2002) Aspects of nurse education programmes that frequently cause stress to nursing students-fact-finding sample survey. Nurse Educ Today 22: 203-211.

18. Potur DC, Bilgin NC (2014) Assessment of clinical stress in male and female nursing students, as measured on the first and last day of the obstetrical nursing clinic course. KASHED 1: 93-106.

19. Karabacak Ü, Ulusoy E, Alpar SE, Bahçecik N (2012) Image of nursing held by nursing students according to gender: A qualitative study. Int J Nurs Pract 18: 537-544. 
Citation: Avdal EU, Arkan B, Uran BNOU (2017) Investigate Stress Levels of Nursing Students in First Oncology Clinical Experience. Adv Practice Nurs 2: 131. doi:10.4172/2573-0347.1000131

Page 5 of 5

20. Çakırcalı E, Tuncer M, Alankaya N, Beytut D, Özgürsoy BN, et al. (2013) Anxiety and stress levels of nursing students at first clinical experience.

21. Arabacı LB, Korhan EA, Tokem Y, Torun R (2015) Pre-clinical and postclinical anxiety and stress levels of first-year nursing students and factors affecting them. Hacettepe University Nursing Faculty Journal: 1-16.

22. Karagözoğlu S, Özden D, Yıldız FT (2013) The integrated program is the clinical stress level of nursing students and the factors affecting them. Anadolu Nursing and Health Sciences Journal 16: 89-95.
23. Yildiz FU, Ozbas A, Cavdar I, Yildizeli TS, Onler E, et al. (2015) Assessment of nursing students' stress levels and coping strategies in operating room practice. Nurse Educ Pract 15: 192-195.

24. Atay S, Yllmaz F (2011) First clinical stress levels of high school students. Anadolu Nursing and Health Sciences Journal 14: 32-37. 